\title{
ESTUDO MICROANATÔMICO DA FISSURA COROIDÉIA NA ABORDAGEM DOS VENTRÍCULOS E CISTERNAS CEREBRAIS
}

\author{
Gustavo R. Isolan', Evandro de Oliveira², Rodolfo Recalde ${ }^{3}$
}

\begin{abstract}
RESUMO - A fissura coroidéia é uma estreita fenda situada na parte medial dos ventrículos laterais, em formato de " $\mathrm{C}$ ", entre o fórnix e o tálamo e onde o plexo coróide se adere. O fato de não haver tecido nervoso en treo epêndima e a pia-máter ao longo deste acidente anatômico torna-o uma importante via no acesso aos ventrículos e cisternas cerebrais. Foram estudados cinco cére b ros, injetando-se artérias e veias com material siliconado colorido e cinco cére b ros sem realce colorido dos vasos, num total de 20 hemisférios cerebrais. Foram analisadas e revisadas as relações neurais, arteriais e venosas, bem como as abordagens cirúrgicas em cada parte da fissura coroidéia. Concluiu-se que o conhecimento prévio detalhado desta microanatomia é fundamental para os neuro c i ru rgiões que vão abordar lesões nos ventrículos e cisternas cerebrais, pois se obtém uma noção tridimensional que será indispensável durante o ato cirúrgico.
\end{abstract}

PALAVRAS-CHAVE: fissura coroidéia, anatomia microcirúrgica, ventrículos cerebrais.

\section{Microanatomical study of the choroidal fissure in ventricular and cisternal approaches}

ABSTRACT - The choroidal fissure is a narrow cleft in the medial part of the lateral ventricle, in a C-shaped a rc, between the fornix and the thalamus, where the choroidal plexus join. Due to absence nervous tissue between ependima and pia-mater along this invagination, it is an important route in brain ventricles and cisterns. Five brains were studied by injecting colored silicone arteries and veins and five brains without colored silicone, in a total number of 20 brain hemispheres. It was analized and revised the neural, arterial and venous relationships and surgical approaches in all parts of the choroidal fissure. In conclusion, the p revious knowledge detailed this microanatomy is primordial for neuro su rgeons that will approach brain ventricular and cisternal lesions because the neuro su rgeons gain a tridimensional notion that will be indispensable during surgery.

KEY WORDS: choroidal fissure, microsurgical anatomy, brain ventricles.

A fissura coroidéia é uma estreita fenda situada na parte medial dos ventrículos laterais, em formato de " $C$ ", entre o fórnix e o tálamo e onde o plexo coróide se adere ${ }^{1,2}$. O fato de não haver tecido nervoso entre o epêndima e a pia-máter ao longo deste acidente anatômico torna-o importante via de acesso a várias estruturas anatômicas, as quais são muitas vezes impossíveis de serem expostas sem lesão de estruturas que levariam a variados déficits neurológicos.

Dessa forma, o estudo microanatômico da fissura coroidéia é parte fundamental do aprendizado no laboratório de microcirurgia para neurocirurgiões que desejam abordar os ventrículos laterais, tercei roventrículo e cisternas da base do cére bro.

\section{MÉTODO}

O estudo foi realizado com utilização de bancada e microscópio cirúrgico com magnificação de 3 e 40 vezes e instrumental microcirúrgico em cinco cérebros com a rtérias e veias injetadas com material siliconado colorido e em cinco cérebros sem realce colorido dos vasos, num total de 20 hemisférios cerebrais, após ter sido aprovado pelo comitê de ética (HBP - protocolo 250/5).

Utilizou-se silicone com corante vermelho para perfundir as artérias e com corante azul para perfusão venosa. As peças anatômicas foram submetidas a secções axiais, co ronais e sagitais, bem como às abordagens transcorticais e transcalosa para acessar os ventrículos e cistemas da base.

\footnotetext{
Laboratório de Microciru rgia, Hospital Beneficência Portuguesa de São Paulo (HBP) e Instituto de Ciências Neurológicas (ICN), São Paulo SP, Brasil: ${ }^{1,3}$ Neurocirurgão, Laboratório de Microcinurgia do HBP; ${ }^{2}$ Neurocinurgião, Diretor do ICN, Professor do Departamento de Neurocirurgia da Universidade Estadual de Campinas, (UNICAMP), Campinas SP, Brasil.

Recebido 4 Junho 2004, recebido na forma final 5 Abril 2005. Aceito 19 Maio 2005.

Dr. Evandro de Oliveira - Instituto de Ciências Neurológicas - Praça Amadeu Amaral $27 / 5^{\circ}$ andar - 01327-010 São Paulo SP - Brasil. E-mail: icne@uol.com.br
} 


\section{RESULTADOS}

A fissura coroidéia foi dividida em corpo, parte atrial e parte temporal. O corpo localizou-se entre o corpo do fórnix e a superfície superior do tálamo. A parte atrial encontrou-se entre o atrium do ventrículo lateral e a crura do fórnix e pulvinar do tálamo. A parte temporal foi aquela situada entre a fímbria do fórnix e a superfície inferolateral do tálamo. Essa última se estendia do forame de Monro, contornando as superfícies superior, posterior e inferior do tálamo, até o ponto coroideo inferior, localizado logo atrás da cabeça do hipocampo e lateralmente ao corpo geniculado lateral (Figs 1 e 2).

Identificaram-se em todos os encéfalos a tela coroidéia, membrana na qual o plexo coróide se originava. A tela coroidéia aderia-se à superfície talâmica da fissura coroidéia através de discreta proeminência chamada taenia thalami ou taenia choroidea.

O corpo da fissura coroidéia estava situado no corpo do ventrículo lateral entre o corpo do fórnix e a superfície superior do tálamo. Essa porção da fis- sura coroidéia foi acessada pela abordagem interhemisférica transcalosa com o objetivo de expor o teto do terceiro ventrículo. As colunas do fórnix, que constituem a parede anterior do forame de Monro, formavam as partes posterior e inferior da pare de medial do corno frontal. As veias que drenam o corno frontal e corpo do ventrículo lateral passavam através das margens da fissura coroidéia para converg i rem no velum interpositum, A camada mais inferior que constituia o teto do terceiro ventrículo estava formada por tela coroidéia, que se aderia à taenia thalami, localizada na borda livre da estria medular do tálamo.

As artérias relacionadas ao corpo da fissura coroidéia eram ramos terminais das artérias coro idéias póstero-laterais e póstero-mediais, sendo identificadas na totalidade dos casos. As artérias coroidéias póstero-mediais tiveram origem da porção proximal da artéria cerebral posterior e cursavam paralela e medialmente a esta nas cisternas basais, alcançando a área adjacente à glândula pi-

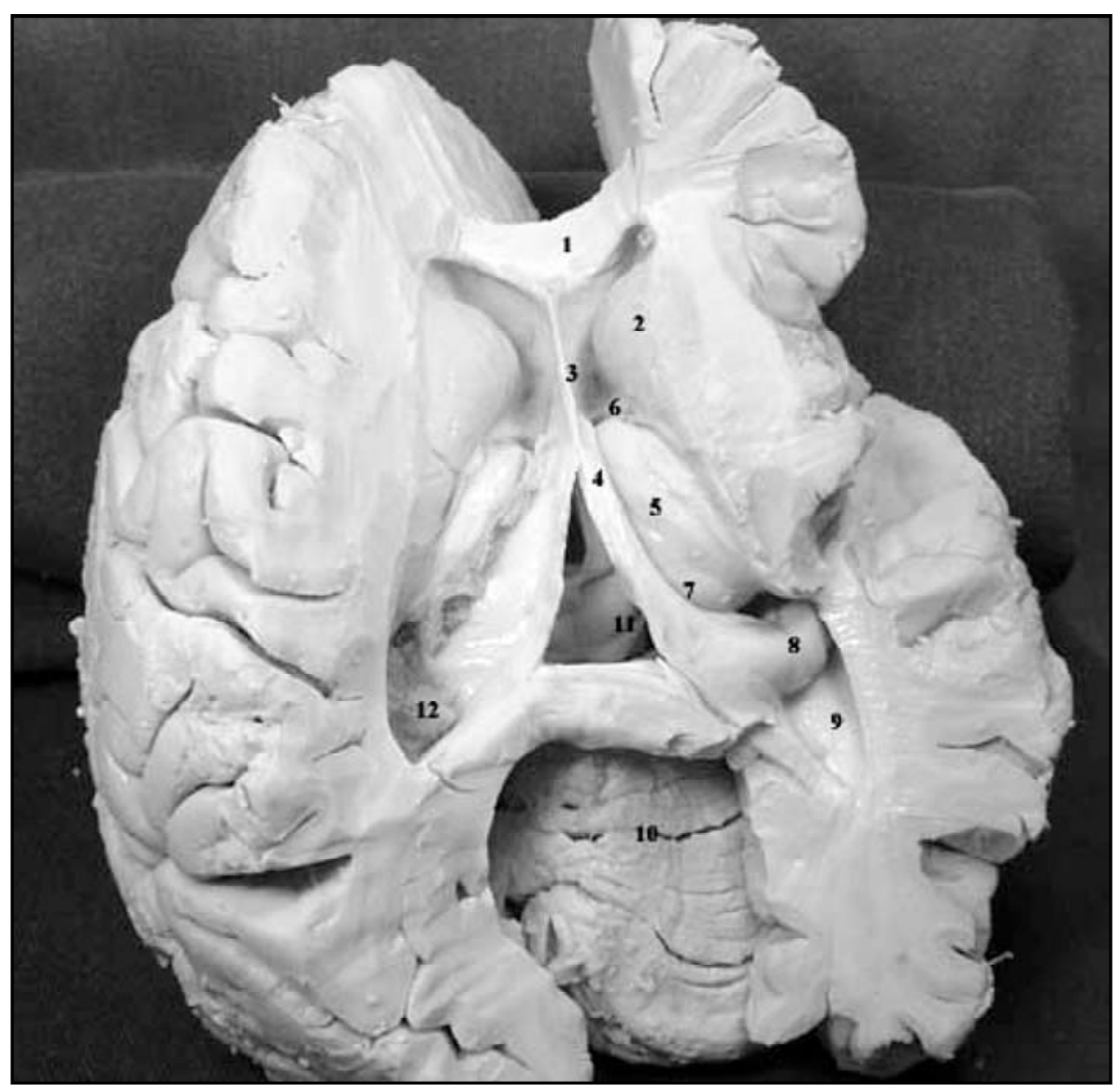

Fig 1. Visão superior de cortes axiais dos hemisférios cerebrais 1. joelho do corpo caloso, 2. cabeça do núcleo caudado, 3. septo pelúcido, 4. fórnix, 5. tálamo, 6. forame de Monro, 7. fissura coroidéia, 8. hipocampo, 9. atrium, 10. cerebelo, 11. técto do mesencéfalo, 12. glômus do plexo coróide no atrium do ventrículo lateral. 


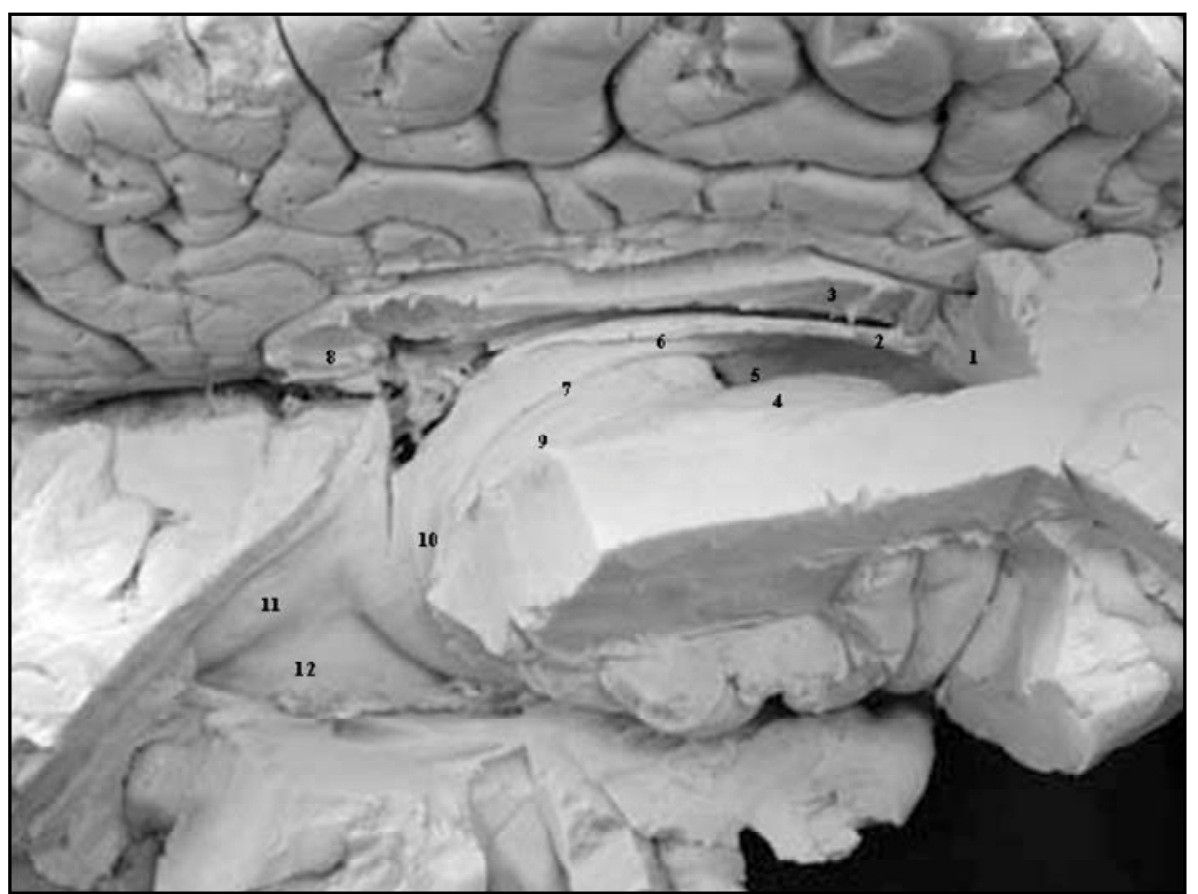

Fig 2. Dissecção do hemisfério cerebral direito, 1. joelho do corpo caloso, 2. corno frontal do ventrículo lateral, 3. corpo do corpo caloso, 4. cabeça do núcleo caudado, 5. coluna do fómix (limite anterior do forame de Monro), 6. corpo do fórnix, 7. corpo da fissura coroidéia, 8. es plênio do corpo caloso, 9. tálamo, 10. crura do fórnix, 11. bulbo do caloso, 12. calcar avis.

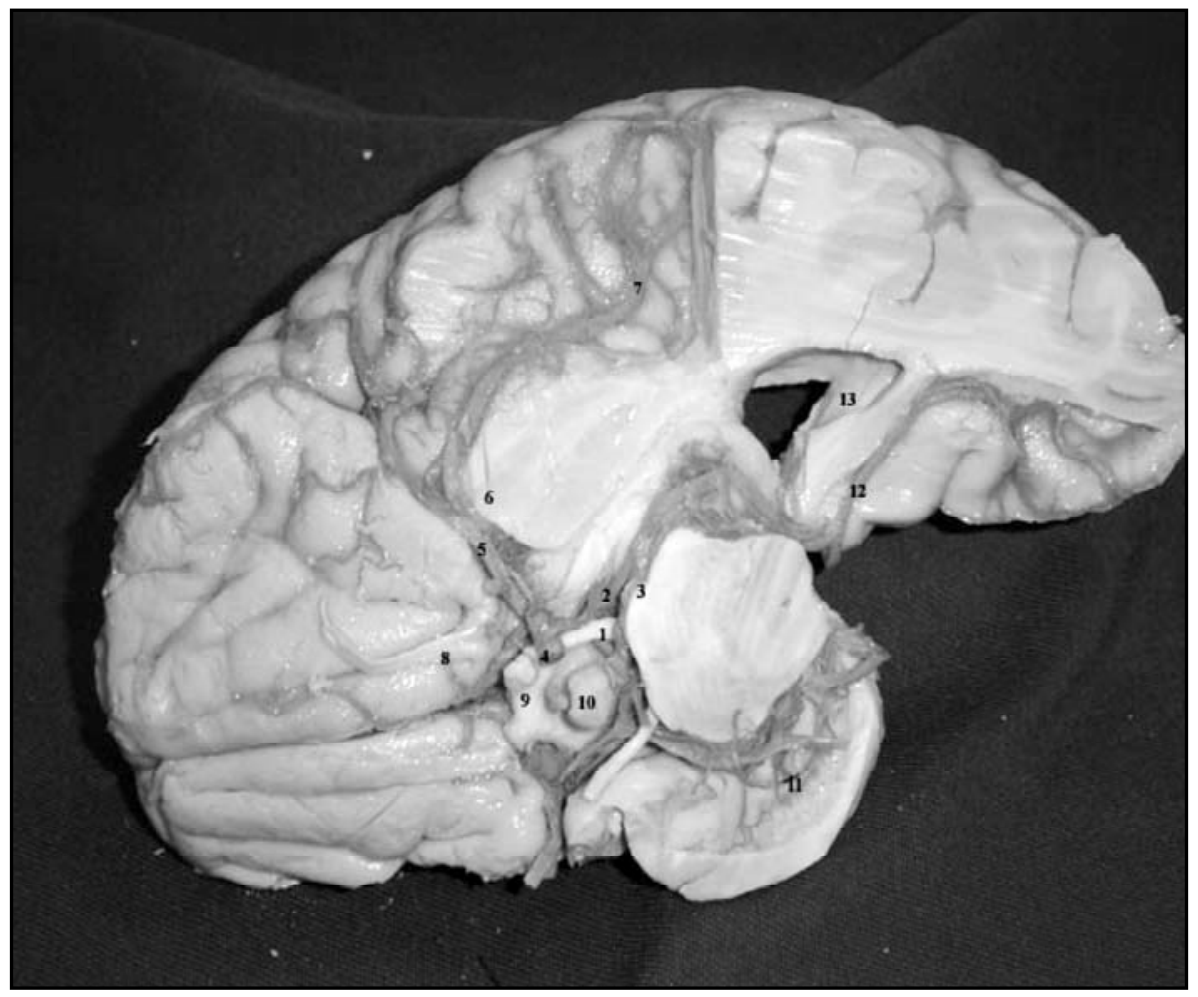

Fig 3. Visão inferior das artérias cerebrais. 1. nervo oculomotor 2. artéria cerebral posterior (segmento P2A) 3. artéria coroidéia póstero-medial, 4. artéria carótida interna, 5. artéria ce rebral média, 6. límen da insula, 7. artéria cerebral média (segmento M3), 8. nervo olfatório, 9. quiasma óptico, 10. glândula pituitária, 11. artéria coroidéia póstero-lateral, 12. artéria ce rebral posterior (segmento P4), 13. corno occipital do ventrículo lateral. 
neal; a partir daí se curvavam e adentravam no ve lum interpositum, indo suprir o plexo coróide no teto do terceiro ventrículo. As artérias coroidéias póstero-laterais tiveram origem na artéria cerebral posterior, distal a origem das artérias coroidéias póste romediais em todos os casos (Fig 3). Seus ramos alcançaram o plexo coróide dos ventrículos laterais, passando diretamente de sua origem através das porções atrial e temporal da fissura coro idéia em todos os cére bros injetados, para então se dirigirem ao corpo do ventrículo lateral .

As veias relacionadas ao corpo da fissura coroidéia foram as veias ventriculares, que se originavam no corno frontal e corpo do ventrículo lateral, e as veias cerebrais internas. As veias ventriculares fo rmavam dois grupos: medial e lateral. O grupo medial era constituído pelas veias septais anterior e posterior e o grupo lateral pelas veias talamoestriada, talamocaudada e veias caudadas anterior e posterior, embora estas duas últimas tenham sido identificadas em somente dois hemisférios injetados. As veias do grupo lateral eram mais largas do que as do grupo medial e penetravam na taenia cho roideia para alcançar o velum interpositum. A veia talamoestriada, uma larga veia situada sobre o sulco entre o núcleo caudado e o tálamo, angulava-se posteriomente próximo ou na altura da margem posterior do forame de Monro para entrar novelum interpositum, unindo-se com a veia cerebral interna.

Parte temporal da fissura coroidéia - A parte temporal da fissura coroidéia foi identificada na pa rede medial do corno temporal, entre a fímbria do fórnix e a parte inferolateral do tálamo. O ponto coroideo inferior constituiu o limite inferior da fissura coroidéia e estava localizado entre o corpo geniculado lateral e a cauda do núcleo caudado, em uma região logo atrás do núcleo amigdalóide. O plexo coróide adería-se à margem da fímbria do fó rnix através da taenia fimbriae e à margem inferolateral do tálamo através da taenia choroidéia. Através das partes temporal e atrial da fissura coroidéia foram abordadas e dissecadas as cistern as c rural, ambiens e quadrigeminal. Através da parte temporal foram expostas as estruturas da cisterna ambiens. Esta estava delimitada medialmente pelo mesencéfalo, superiormente pelo pulvinar do tálamo e lateralmente pela face medial do lobo temporal, onde era formada por três faixas longitdinais de tecido nervoso divididas no sentido ínfero-superior em subiculum, giro dentado e fímbria do fórnix. Estas estruturas foram identificadas em todos os casos. A fissura coroidéia estava localizada logo acima da fímbria. A cisterna crural foi abordada pela fissura coroidéia somente quando foi realizada incisão no nível do ponto coroideo inferior através do núcleo amigdalóide e úncus.

As artérias expostas pela microdissecção da parte temporal da fissura coroidéia foram as artérias cerebral posterior, coroidéia anterior, coroidéia póstero-medial e coroidéia póstero-lateral. Todas elas cursavam no local correspondente à cistern a ambiens. Os ramos tálamo-geniculados da artéria c e rebral posterior tiveram origem na cisterna am biens próximo ao limite inferior da fissura coroidéia e passavam em íntima relação aos corpos geniculados para alcançar o tálamo e a porção adjacente da cápsula interna, porém não foram idenficados em três dos cére bros injetados. As artérias tálamoperfurantes estavam situadas anteriormente ao mesencéfalo. A artéria coroidéia anterior teve origem da artéria carótida interna em todos os casos e cursava posteriormente entre o pedúnculo cerebral e o úncus e inferiormente ao trato óptico.

As veias identificadas na parte temporal da fissura coroidéia, e que passavam através desta, formavam dois grupos. Um grupo medial, situado no teto e parede lateral do corno temporal, e um lateral, situado no assoalho deste. Este último era sendo drenado pelas veias hipocampais transversas. A veia coroidéia inferior era constituída pela confluência das veias do grupo medial. Ela cursava sobre o plexo coróide do corno temporal e passava pela fissura coroidéia próximo ao ponto coroideo inferior para desembocar na veia basal. Estes achados relativos à anatomia do sistema venoso, porém, não foram claramente identificados em todos os encéfalos.

Pa rte atrial da fissura coroidéia - A parte atrial da fissura coroidéia estava situada entre a crura do fórnix e o pulvinar do tálamo e sua microdissecção expôs a cisterna quadrigeminal. As paredes laterais da cisterna quadrigeminal evidenciavam uma parte anterior, formada pela crura do fórnix, e uma posterior, formada por parte da superfície medial do lobo occipital. Na parede anterior da cisterna quadrigeminal foram identificadas uma parte medial, formada pela lâmina quadrigêmia, e uma parte lateral, formada pela porção do pulvinar que se correlacionava medialmente com a crura do fórnix. Abaixo do colículo, a cisterna quadrigeminal estendeu-se na fissura cerebelo-mesencefálica. $O$ assoalho da cisterna estava constituído pela superfície inferior do esplênio. 
A artéria cerebral posterior entrava na cisterna quadrigeminal e cursava na porção inferior e lateral desta. As artérias coroidéias póstero-mediais entravam nesta cisterna oriundas da cisterna am biens e cursavam acima da veia basal e abaixo da veia cerebral interna, alcançando a região da pineal. A partir daí se curvavam para adentrar no velum in terpositum. As artérias coroidéias póstero-laterais passavam lateralmente ao pulvinar e através da fissura coroidéia dirigindo-se para o plexo coróide, o atrium e o corpo do ventrículo. A artéria cerebelar superior cursava na parte inferior da cisterna quadrigeminal, mas não pode ser alcançada abordando-se a fissura coroidéia em nenhum caso.

A veia cerebral interna emergia do velum inter positum e a veia basal, da cisterna ambiens, para se confluírem na veia de Galeno. Além destas, foram identificadas as veias atriais mediais e laterais. Outras veias que convergiam na porção superior da cisternaeram as veias pericalosas posteriores, que cursavam em torno do esplênio do corpo caloso, e as veias occipitais internas, que tinham origem próximo da fissura calcarina e sulco parieto-occipital. Todas essas veias foram identificadas nos cére b ros injetados.

\section{DISCUSSÃO}

Descrições detalhadas da anatomia microcirúrgica dos ventrículos laterais e terce iro ventrículo foram publicadas previamente ${ }^{1-4}$. Os vasos dos cinco cére $b$ ros que não foram injetados com contraste foram dissecados e ressecados para melhor visualização dos detalhes anatômicos não relacionados à vascularização.

A abordagem cirúrgica da fissura coroidéia deve ser realizada através da taenia fornicis e taenia fim briae, e não através da taenia choroidea, porque nessa entram ramos das artérias coroidéias pósteromediais e póstero-laterais e saem as veias tálamoestriada, tálamo-caudada, atrial lateral e ventricular inferior. Isso equivale a dizer que não existe relação íntima das artérias coroidais ou grande veias com o lado fornicial da fissura coroidéia ${ }^{1,2}$.

Devido à inexistência de tecido neural desenvolvido entre o epêndima e a pia-máter que form am a fissura coroidéia, esta torna-se uma importante via de acesso cirúrgico através dos ventrículos laterais para abordar lesões em estruturas profundas do cérebro ${ }^{1,5}$. Acessando a fissura coroidéia pelo corpo do ventrículo lateral tem-se acesso ao velum inter positum e ao terceiro ventrículo, pelo atrium do ventrículo lateral tem-se acesso à cisterna quadri- geminal, região da pineal e parte posterior da cisterna ambiens, e pelo lobo temporal tem-se acesso às estruturas das cisternas ambiens e crural.

No planejamento cirúrgico é fundamental a relação da cápsula interna com as paredes ventriculares, sendo o braço anterior da cápsula interna separado do corno frontal pela cabeça do núcleo caudado, o braço posterior separado do corpo do ventrículo lateral pelo tálamo, e o joelho da cápsula inte rra tendo contato direto com a parede ventricular ao nível do forame de Monro.

O corpo da fissura coroidéia é usualmente exposto através de uma incisão transcortical no giro f rontal médio ou uma incisão transcalosa anterior através do joelho e corpo do corpo caloso. Preferese esta última quando os ventrículos são de tamanho n o rmal ou discretamente dilatados ${ }^{1,2}$. No decorre $r$ do acesso cirúrgico, após abertura do ventrículo, o forame de Monro é encontrado seguindo-se a veia tálamo-estriada e o plexo coróide anteriorm e nte. Algumas vezes, o lado ventricular oposto à abordagem pode ser aberto. Para correta orientação sobre qual lado ventricular está sendo exposto, devese ter em mente que a veia tálamo-estriada está a direita do plexo coróide no lado ventricular direito e a esquerda no lado ventricular esquerdo. Além disso, a desorientação anatômica transoperatória pode ocorrer quando existe o cavum do septo pelúcido, pois não há estruturas ventriculares neste espaço da linha média.

Após ser obtida orientação anatômica dentro do ventrículo lateral pode-se abordar a parte anterior do terc e i roventrículo por incisão da coluna do fórnix ou, preferencialmente, pelas abordagens transcoradéia ou transfornicial. Nestas últimas, as estruturas anatômicas são afastadas ao invés de seccionadas. No acesso transcoroideo a taenia for nicis pode ser aberta do forame de Monro até o atrium do ventrículo lateral. Visualiza-se nessa abordagem a primeira camada do teto do terceiroventrículo, que é a membrana superior de tela coro idéia. Nesse estágio as veias cerebrais internas e ramos da artéria coroidéia póstero-medial podem ser identificados ${ }^{6}$. O próximo passo será a dissecção entre as duas veias cerebrais internas. As duas últimas camadas a serem expostas são a membrana inferior de tela coroidéia e o plexo coróide do terceiro ventrículo, que podem ser abertos na linha média. A cavidade do terce iroventrículo, aderência intertalâmica, quando presente, e o assoalho do terceiro ventrículo podem ser completamente visualizados por esse acesso sem que nenhuma estru- 
tura neural tenha sido sacrificada. No caso de expandir o acesso, a veia septal anterior será a única estrutura que poderá ser sacrificada, uma vez que oclusão da veia tálamo-estriada pode causar infarto hemorrágico dos gânglios da base. Deve-se atentar ao fato de que o joelho da cápsula interna está em íntima relação com a parede ventricular ao nível do forame de Monro, logo, uma retração desproporcionada com o afastador poderá lesar essa estrutura ${ }^{7-9}$.

Aborda-se a parte temporal da fissura coroidéia para lesões situadas na parte medial do lobo temporal e cisterna ambiens, com a vantagem de se expor as artérias cerebral posterior, coroidéias posterior e anterior e a veia basal sem importante retração do lobo temporal. Comumente, realiza-se corticotomia na porção anterior do giro temporal médio no hemisfério não dominante e no giro temporal inferior, visando a diminuição da possibilidade de dano às radiações ópticas no hemisfério dominante. Outra possibilidade de minimizar este dano é através de corticotomia no giro temporal inferior, occípito-temporal ou ao longo do sulco colateral. Ao adentrar no corno temporal visualiza-se a fissura coroidéia e ramos das artérias coroidéias anterior e póstero-laterais, entrando no plexo coróide, bem como a veia ventricular inferior, cursando no teto, e as veias hipocampais transversas, no assoalho do corno temporal. O plexo coróide é retraído para cima e a fissura é aberta ao longo da taenia fimbriae. Quando existe lesão na cisterna crural, a incisão é realizada ou extendida anteriormente ao ponto coroideo inferior, ou seja, através do núcleo amigdalóide e úncus. Isto permite ao neurocirurgião abordar o segmento P1 da artéria cerebral posterior e o topo da artéria basilar ${ }^{10}$. Deve-se ressaltar que dano unilateral no fórnix ou formação hipocampal não produzem déficits, da mesma maneira que lesões do núcleo amigdalóide ou da estria terminal unilateralmente. Por outro lado, lesão bilateral do núcleo amigdalóide causa distúrbio emocional e lesão bilateral da formação hipocampal causa déficit de memória recente.
Finalmente, o acesso pela porção atrial da fissura coroidéia irá expor a cisterna quadrigeminal, a região da pineal e a parte posterior da cisterna ambiens. Pode ser abordada por corticotomia nos giros temporais médio e superior, junção temporo-parietal e lóbulo parietal superior, sendo dada preferência a este último, uma vez que a abordagem pela região temporo-parietal pode lesar as radiações ópticas, causando hemianopsia em ambos os hemisférios, distúrbios da função visuo-espacial no hemisfério não dominante, e afasia com agnosia no hemisfério dominante. Ao visualizar-se o atrium do ventrículo retrae-se o glômus do plexo coróide, visando encontrar a taenia fomicis, a qual será aberta. A retração da crura do fórnix medialmente e posteriormente expõe a cisterna quadrigeminal e a parte posterior da cisterna ambiens, porém, esta deve ser realizada com parcimônia para evitar lesão do calcar avis, com conseqüente distúrbio visual.

Em conclusão o estudo microanatômico da fissura coroidéia e de suas relações são fundamentais para os neurocirurgiões que tenham como objetivo a b o rdar as cisternas da base com minimização dos riscos cirúrgicos, pois o exercício de visualização destas estruturas no laboratório de microcinurgia, mediante variados ângulos, fornece uma noção tridimensonal da região.

\section{REFERÊNCIAS}

1. Rhoton AL Jr. The cerebrum. Neurosurgery 2002;51(Suppl)1S:1-S51.

2. Rhoton AL Jr. The lateral and third ventricles. Neurosurgery 2002; 51(Suppl1)S:207-S271.

3. Yamamoto I, Rhoton AL Jr, Peace D. Microsurgery of the third ventricle: microsurgical anatomy. Neurosurgery 1981;8:334-356.

4. Wen HT, Rhoton AL Jr, Oliveira E. Transchoroidal approach to the third ventricle: an anatomic study of the choroidal fissure and its clinical application. Neurosurgery 1998;42:1205-1219.

5. Nagata S, Rhoton A L Jr, Barry M. Microsurgical anatomy of the choroidal fissure. Surg Neurol 1988;30:3-59.

6. Rhoton AL Jr. The supratentorial arteries. Neurosurgery 2002;51(Suppl 1):S53-S120.

7. Rhoton AL Jr. The cerebral veins. Neurosurgery 2002;51(Suppl 1):S159-S205.

8. Lavyne MH, Patterson RH Jr. Subchoroidal trans-velum interpositum approach to mid-third ventricular tumors. Neurosurgery 1983;12:86-94.

9. Ono M, Rhoton A L Jr, Peace D, Rodrigues R. Micro su rgical anatomy of the deep venous system of the brain. Neurosurgery 1984;15:621-657.

10. Ikeda K, Shoin K, Mohri M, et al. Surgical indications and microsurgical anatomy of the transchoroidal fissure approach for lesions in and around the ambient cistern. Neurosurgery 2002;50:1114-1119. 